\title{
From Comparative Philosophy to Fusion Philosophy
}

ELISE COQUEREAU

University of Vienna (Austria) and Charles University in Prague (Czech Republic) (elise.coquereau@hotmail.fr)

ed. ARINDAM CHAKRABARTI and RALPH WEBER, Comparative Philosophy Without Borders, London and New York: Bloomsbury Academic. 2016, 246 pp.

This innovative book consists of nine essays and puts forth an extensive methodology for a redefined comparative philosophy, as presented in the Introduction (1-33) and Afterword/Afterwards (227-39) written by Arindam Chakrabarti and Ralph Weber. The nine essays by Tom J. F. Tillemans, Barry Hallen, Chien-hsing Ho, Laurie L. Patton, Arindam Chakrabarti, Masato Ishida, Ralph Weber, Sari Nusseibeh and Sor-hoon Tan draw on various philosophical traditions (from the Asian, Western, African and Arabic worlds), academic fields (linguistics, political philosophy, epistemology, etc.) and topics (translation, perception, other-consciousness, justice, authority, etc.), in order to effectuate what 'Comparative Philosophy Without Borders' could be. The clear aim of these essays is to demonstrate and put into practice the methodology presented by the two editors and authors, according to whom performing comparative philosophy transcends establishing it through norms. This definitely constitutes a successfully treated challenge, not only by the authors, but even more by the editors.

In their Introduction and Afterword/Afterwards, Arindam Chakrabarti and Ralph Weber defend the idea of a "fusion philosophy" as the next step for a transformation of comparative philosophy, which means 'philosophizing' rather than doing comparative philosophy, but a philosophizing that would already be crosscultural. As a next step in this transformation, fusion philosophy means "philosophically comparing" rather than simply "comparing philosophies" (235). The editors ground this view on the by now well-known but still persisting (political) reality of overall western-centric academics, as well as on the internal conceptual developments within the field of comparative philosophy. They divide these developments into three stages. Roughly summarized, the first stage consists in finding equivalents in non-Western philosophies that would anticipate Western philosophies; the second stage attempts to contrast these philosophies; the third stage aims at reinterpreting Western philosophies by using contribution of non-Western theories (and vice versa). The editors argue for jettisoning the epithet 'comparative' and for doing fusion philosophy without the intentional framework of juxtaposing and comparing Western and non-Western philosophies. Instead, one should raise and solve problems by using different traditions, which would constitute a fourth stage in the development of comparative philosophy. In order to reach this stage, they encourage their readers to take the risk of breaking from the security of a parallel global history of ideas. Such a history merely seeks to complete Western-oriented categories through the contribution of their non-Western counterpart, while nevertheless retaining the general categorization established in Western philosophies (for example, the established division between epistemology, ethics, aesthetics, etc.). They also suggest dissolving the comfortable descriptive juxtaposition of ideas from different cultural traditions, which does not promote critically questioning the concepts, but simply exposing their contrasts (for example, looking at the differences of Aristotelian and Buddhist logics). On the contrary, they argue for a questioning and thinking that would cross all borders, whether cultural, methodological or disciplinary. Ideally, 'fusion' or 'comparative' philosophy should become tautological when philosophy is 
grounded in a plurality of traditions, methodologies, styles and fields that would provide us with new insights on classical problems, or new problems based on insights that are multiple in their origins. 'Difference' and 'plurality' that are so relevant to comparative philosophy would then shift, from the acknowledgment of the difference of traditions, or the cultural differences of the comparanda, to the differences in the results produced by reasoning, which should reach a philosophical and conceptual newness. This conceptual newness means the ability to bring to light new problems that have not been raised in a particular tradition due to its own presuppositions and limits, and solve other problems with the help of different conceptual structures and reasoning that provide new materials for thinking and new ways of approaching and reflecting on a problem.

No doubt, such a challenging and self-critical account of comparative philosophy is long overdue and Chakrabarti's and Weber's argumentation provides us with a sound and ambitious definition for the future of fusion philosophy. As is often the case with an edited volume, the readership will be disparate: experts of a particular field or investigating a precise question will highly benefit from the expertise of the single articles. Yet, it is the eclectic reader, who has the patience and curiosity required for embarking on so many detours through various traditions and topics, that will benefit the most from the project as such, for she will develop the possibility to practice fusion philosophy itself, thanks to the methodological account of the authors but even more so to the different applications of fusion the book offers through its innovative essays.

However, regarding the project as a whole, further questions could still be addressed to the authors and editors. Are there limits for a particular person P to do fusion philosophy? Can we hope for a 'complete' and 'global' fusion philosophy (in terms of traditions, but also styles, disciplines, etc.) made by limited individual P? If we can, how are we able to transcend the unconscious and internal imbalances (or subjections?) that also constitute our academic education and conceptual structures? Indeed, if the external criticism against the closure of the Western academic world is described at length, should not other difficulties, in particular the ones intrinsic to different philosophical traditions (such as the difficulties of the academic world in India, China, Africa, etc.) also be taken into consideration? Should we not also engage in a critical view of recent crosscultural methodologies? Establishing these different levels of a politico-cultural academic situation could result in a multidimensional analysis of the problem, which is partially lacking from the nine chapters.

For example, a majority of the essays take as their starting point a particular problem common to Western philosophy that they question, or find deficiencies in, or philosophize from, through the resources of non-Western traditions that unveil new aspects of the discussion. This is the case for example in the articles of Tom J. F. Tillemans, Barry Hallen, Ralph Weber, Sari Nusseibeh and Sor-hoon Tan. The prejudices of the English language in the case of translation (Tilleman and Hallen), or the problems of applying a Western concept of justice in the world (Nusseibeh and Tan) are surely relevant problems that require critiques and alternatives. But are there not just as many intracultural problems, or problems from within a given nonWestern tradition, that could be analyzed and criticized from another non-Western tradition, or problems that originate from a non-Western tradition that could be thought anew by the Western tradition?

It seems that the internal borders within the established field of comparative philosophy still direct and frame the comparisons of this work. Therefore, one could question the very title of the book: can we actually "philosophize without borders"? The fact that all the authors intentionally modify, shift and fuse classical or established borders in a creative way does not mean that they do not unintentionally erect new borders. Are we not therefore crossing borders only to encounter new ones? Arindam Chakrabarti and Ralph Weber write about possible intercultural connections in the domain of philosophy of mind and language (230) which might point to some conventional ways of drawing comparisons that are de facto located within certain borders. In other words, even within cross-cultural studies, it seems that only some methodologies or topics are acceptable because they fit a certain persisting Western-centric framework (preferably logics, philosophy of mind, linguistic, etc.). Which degree of heterogeneity can we accept that would still enable cross-cultural

Journal of World Philosophies 1 (Winter 2016): 152-154

Copyright (C) 2016 Elise Coquereau.

e-ISSN: 2474-1795 • http://scholarworks.iu.edu/iupjournals/index.php/jwp • doi: 10.2979/jourworlphil.1.1.13 
understanding? What are therefore the criteria that could justify erecting one border rather than another? Indeed, in the essays in question, a majority of authors write in an analytical, predominantly Anglo-American philosophical style (Barry Hallen, Chien-hsing Ho, Arindam Chakrabarti, Masato Ishida) about cross-cultural topics. Whether a possible reformulation of a classical Western problem could gain some explanation or insights through the confrontation with another perspective and style is a question that persists in these essays. How to reverse this direction of analysis is debatable, but the question whether borders could be 'eliminated' should also be raised.

Elise Coquereau is a $\mathrm{PhD}$ Student in Philosophy at the University of Vienna (Austria) and Charles University in Prague (Czech Republic). She graduated from the Erasmus Mundus Master Program (Europhilosophie) and has also studied in New Delhi (Jawaharlal Nehru University), Brazil (Universidad Federal de São Carlos) and Luxembourg (Université du Luxembourg). She works in intercultural philosophy, in particular on questions concerning intercultural hermeneutics and methods to think Otherness, with a particular focus on contemporary Indian philosophy. Her $\mathrm{PhD}$ research questions the concept of dialogue in Daya Krishna's project of samvāda, i.e. dialogues between Indian philosophical traditions. 